The Agriculturists 14(2): 113-123(2016) ISSN 2304-7321 (Online), ISSN 1729-5211 (Print)

A Scientific Journal of Krishi Foundation

Indexed Journal

Impact Factor: 0.402 (GIF, 2014)

Review Article

\title{
Climate Change Vulnerabilities of Woman in Bangladesh
}

\author{
Nishith Zahan Tanny* and M. Wakilur Rahman \\ Dept. of Rural Sociology, Bangladesh Agricultural University, Mymensingh-2202, Bangladesh \\ *Corresponding author and Email: tonny0819@gmail.com
}

Received: 20 September $2016 \quad$ Accepted: 12 December 2016

\begin{abstract}
This paper reviews the existing literature on gender differentiated climate change vulnerabilities in developing countries including Bangladesh. It is evident that climate change amplifies the vulnerabilities of poor people who are marginalized and more dependent on the threatened natural resources. Among the poor people women are seemed to be disproportionately affected by climate change. The review took utmost effort to unfold the root causes of gender differentiation under climate change scenario. It identifies some governing factors such as ownership, political affiliation, labor force participation that determine the extent of the effect of climate change. Deeper analyses of the literatures indicate that 'gender differentiated impacts'- are directly related to traditional gender roles of women. It also reveals the constraints to women's adaptation resulting from access to resource allocation and other elements of society. Drawing lessons from the existing literatures, finally it outlines some of the policy options to ensure the inclusion of women in development arena.
\end{abstract}

Keywords: Climate change, Gender, Vulnerability, Adaptation.

\section{Introduction}

Climate change is one of the emerging challenges for the world community. It results from natural variability or human activity that can alter the composition of global atmosphere and this alteration is observed over a comparable period of time. Basically, some specific regions or groups have to pay the cost of this alteration. There is a real risk that the climate changes will accelerate the gap between the developed and the developing world through enhancing the gap between men and women in the developing countries. Because women in developing countries are the marginalized group with no voice and are underrepresented, both at the community level and in the international negotiations on climate change. Moreover, women's higher dependence on climate sensitive agriculture sector as well as injustice of opportunities further enhances their submissive gender role. The gender differences are not the inevitable products of biological sex (Annecke, 2005; Money, 1986) rather it is socially constructed roles, behaviors, attributes, and relative power associated with being female or male in a given society. Perceptions of gender vary widely both within and between cultures, and change over time. But in all cultures, gender determines power and resources for females and males (FAO, 2011). Women's position is generated by discrimination and oppression. These gendered aspects ultimately make the women more vulnerable than men in a given climate change situation. 
The concept of climate change-related vulnerability has been comprehensively reviewed by many authors (O'Brien et al., 2007; Eriksen and Kelly, 2007). Vulnerability in the context of climate change is defined as the degree to which a system is susceptible to the adverse effects of climate change, including climate variability and extremes. Therefore, gender vulnerability to climate change in this context can be defined as the women's exposure to risk and their adaptive capacity to anticipate and respond to environmental hazard.

The definition of the IPCC (2007) reflects three components of vulnerability in the climate change context: (i) exposure, (ii) sensitivity and (iii) adaptive capacity. So, a system is vulnerable if it is exposed and sensitive to the effects of climate change and at the same time has limited capacity to adapt. Similarly, exposure as a component of vulnerability is not only the extent to which a system is subject to climatic variations, but also the degree of these variations. However, even though a system may be considered as being highly exposed and/or sensitive to climate change, it does not necessarily mean that it is vulnerable. This is because neither exposure nor sensitivity account for the capacity of a system to adapt to climate change, whereas vulnerability is the net impact that remains after adaptation is taken into account.

Adaptive capacity is the ability of a system to adjust successfully to climate change that is calibrated to: (a) moderate damages; (b) take advantage of opportunities; and (c) cope with the consequences. Some literatures emphasize the importance of socio-economic factors for the adaptive capacity of a system, especially the role of institutions and governance in determining the ability to adapt to climate change (Williamson et al., 2012; Engle, 2011). Women's adaptive capacity is determined by their ability to cope with and respond to hazard given the environmental and cultural settings.
There is a close connection between the impact of climate change and vulnerabilities. Vulnerable and marginalized people are affected mostly due to the adverse effects of climate change. The developing countries, due to both their geographical position and their social and economic capabilities, are far more vulnerable to the changing conditions than the developed world. The women, primarily those who live in developing countries, are expected to be disproportionately affected by climate change. There are several researches have been conducted in different regions in different dimensions. However, there is a great lack of synthesis information on gender specific climate change vulnerabilities. With this backdrop, this review paper focuses on three major components i) gender differentiated vulnerabilities of climate change, ii) gender specific adaptation priorities and finally iii) proposes some policy options to overcome the existing barriers.

\section{Methods}

The study is based on secondary data where different articles have been collected using various search media like, Google Scholar and particular journal websites. Different key words, for instance, gender, climate change and vulnerability were used during searching articles. Articles were selected based on the relevancy to study's purpose.

\section{Gender Differentiated Vulnerabilities of Climate Change}

In this section, gender specific vulnerabilities in connection to climate change are discussed. The discussion begin with the governing factors of vulnerabilities, then emphasize on gender specific vulnerabilities in respect to health, labor force, water use and management and food security.

\subsection{Governing factors of vulnerabilities}

Poor of the poorest countries are most vulnerable to the negative effects of climate change. As women encompass a disproportionate share of the poor in developing countries especially in communities that are highly dependent on local 
natural resources, these women are likely to be disproportionately vulnerable to the effects of climate change. -"It is increasingly evident that women are at the center of the climate change challenge. Women are disproportionately affected by climate change impacts, such as droughts, floods, and other extreme weather events, but they also have a critical role in combating climate change"- (UN, 2014).

Women are also more vulnerable to the effects of climate change than men, because the socially constructed roles and responsibilities they have within communities and the differentiated power relations make them more disadvantaged (Nellemann et al., 2011; Ribeiro and Chaúque, 2010). A study on gender and climate change in Mozambique reveals that women can access but cannot control over natural resources and other property rights (Ribeiro and Chaúque, 2010). As well, women do most of the reproductive and part of the productive work, while men are only responsible for productive work. There are structural differences between men and women, such as, gender-specific roles in society, work and domestic life (Lambrou and Nelson, 2010). These differences affect the vulnerability and capacity of women and men to adapt to climate change. In the developing world women are disproportionately involved in natural resourcedependent activities, such as agriculture, compared to salaried occupations. Basically, the vulnerability of women dependent on agricultural sector is affected by their relative insecurity of access and rights over resources and sources of wealth such as agricultural land. Land has powerful social, cultural, economic, political and status-defining meanings but women has little access and control over land like many other resources such as livestock, labor, and development resources including credit, agricultural inputs, technologies, trainings, and information. Among them land is the most important asset that households depend upon for agriculture and also for their livelihoods (FAO, 2011). This productive resource is inevitable for farming and food production. People who do not own their land for their own living are more vulnerable to climate change impacts (Hertel, 2010). In fact, women have limited access to land ownership that increases their severity of vulnerability in a given climatic hazard.

Women also have differential control and ownership of livestock within agriculture and household management. Livestock act as a security in times of crises and also as powerful symbols of wealth and property (Verma, 2007). Women's ownership of livestock is shaped and constrained by economic opportunities, opportunity costs of women's labor (Kristjanson et al., 2010), as well as cultural norms, gender biases and power relations. Given that gender relations reflect differential wealth and power, in some contexts, women and children own and handle smaller livestock, which are a crucial part of the food security (Devendra and Chantalakhana, 2002). Undoubtedly, this type of practice is the product of social construction. Nielsen and Reenberg (2010) discussed culture and agricultural production systems (including gender differences in agricultural production) in Africa. They stated that a person's social position is determined more by institutions, ethnicity, and gender than by individual ability.

Women have the ability to own land and to control livestock. The constitutions in many countries guarantee gender equality with respect to land ownership and controlling but practically many laws violate that principle, especially laws dealing with land ownership. Sometimes the customary laws get priority over the formal legal system, resulting in gender biased legal systems (Aoyagi and Shinada, 2011). That's why most often women have to look after the homestead lands and small livestock only. Another crucial reason behind this is their limited access to decision making whether in the household or at community, national or international level. Thus several factors such as poverty, higher dependence on agriculture sector, socially determined skewed power relations, lack of access to productive resources (land, livestock, technology etc.) ultimately make women more 
vulnerable in any hazardous situation particularly in changing climate situation.

\subsection{Gender differentiated vulnerabilities on health and physical security}

During extreme climatic events such as drought, floods and other climate-related disasters, women face additional risks, due to gender inequities that result in disproportional disaster impacts. It is important to understand how men and women are affected differently by climate change.

The literatures show that the natural disasters kill more women than men during and after disasters where the socio-economic status of women is low (Neumayer and Plumper, 2007; Hines, 2007). After the Asian Tsunami, women and children were 14 times more likely to die during natural disaster than men (BRIDGE, 2008; Araujo et al., 2007). This difference in mortality is associated with differences in social structures where girls are not learned with the same skills as their brothers, such as swimming and climbing. Evidences from Bangladesh also show that women in Bangladesh did not leave their house during floods due to cultural constraints on female mobility and those who did were unable to swim during flood (Nellemann et al., 2011; BRIDGE, 2008). This disparity in death rates also indicates women's greater vulnerability based on socialized gender roles rather than on the biological weaknesses of women (WEDO, 2008). The cultural traditions of developing countries make women more vulnerable to the impacts of climate change because most often they are not permitted to participate in public sphere and have limited access to critical information for emergency preparedness (CCC, 2009). Additionally, most of the women carry their small children and food for survival when they move from hazard areas and these kinds of responsibilities slow their escape (Ahmad, 2012).

In climate change situation women's health is also at a great risk. Women and adolescent girls suffer from urinary tract infections because of using toilet during a day as sanitation system is destroyed during disaster (Alam et al., 2008). Women and girls also face barriers to have healthcare services due to a lack of economic assets to pay for healthcare, as well as cultural restrictions on their mobility which may prohibit them from travelling to seek healthcare (BRIDGE, 2008).The pregnant, breastfeeding and menstruating women are at a great risk of compromising their health after disasters. Physical, sexual and emotional violence of women is very common during and after disaster. After a natural disaster, economic and security challenges may lead women to seek temporary relief and shelter in a condition that may make them potential targets for exploitation and human trafficking (Nellemann et al., 2011). Adolescent girls report especially high levels of sexual harassment and abuse in the aftermath of disasters, and complain of the lack of privacy around sleep, washing and dressing that they face in emergency shelters (Bartlett, 2008).

During and disasters women are exposed to violence within and outside home. Their houses do not remain safe for them. Disaster increases the domestic violence towards women as male member loss their job, they use abusive language and torture physically to the female members of the family (Alam et al., 2008). These are the common pictures within most of the climate affected households of rural Bangladesh.

\subsection{Gender differentiated vulnerabilities and food security}

Climate change has detrimental effect on food security covering its four components such as on food production that is in (availability) distribution (access), food utilization and finally food system stability. Climate change creates scarcity of food supply as production is damaged or destroyed. Food prices increase and it makes food more inaccessible to poor people, particularly to poor women who control homestead-based livelihoods suffer from income losses when crops are blown or washed away (Mondal, 2014). So, there is a possibility to suffer from chronic nutritional deficiency. It is 
women who tend to play a greater role in natural resource management and ensuring nutrition at household or family level in rural areas. Pictures of Bangladesh show that after disaster women have to buy vegetables from markets at higher prices. When women cannot manage resources properly, serve food on time and procure relief materials become victim of domestic violence (abusive language or exertion of physical force) by male members of their family (Alam et al., 2008). In the Less Developed Countries (LDCs) women are responsible for the largest part of agricultural production (Farnworth and Hutchings, 2009). Most often women produce, process, manage, and market food while men are responsible for cash crop and larger livestock. In case of trading women also face difficulties. As communication system is collapsed women have to trade within their local areas and have to accept lower prices for their products offered by male buyers from other areas (Mondal, 2014). All these aspects act as hindrance to food security during or after disasters. So due to the gendered aspects the available food items sometimes go beyond accessibility or utilization which further contributes to instability.

\subsection{Gender differentiated vulnerability on water resources}

Water is a crucial resource for maintaining health and sanitation requirements of life. Climate change alters the availability and access to safe and purified water. Climate change leads to increasing frequency and intensity of floods and deteriorating water quality. This is likely to have a particularly harsh effect on women and girls because of their distinct roles in relation to water use and their specific vulnerabilities in the context of disasters. The heavy rainfall and more frequent floods predicted to result from climate change will also increase women's workloads, as they will have to devote more time to collecting water, and to cleaning and maintaining their houses after flooding. In drought-prone areas affected by desertification, the time absorbed by water collection increase as women and children (mostly girls) have to travel greater distances to find water. It is well documented in the gender and climate change literature, that women and girls generally take the responsibility for collecting water for drinking, cooking, washing, hygiene and raising small livestock, while men use water for irrigation or livestock farming, and for industries (Fisher, 2006). These types of gendered tasks like meeting households' water requirements make women more vulnerable during hazards when there is water crisis. Ultimately, women and girls become disproportionately affected due to impact of climate change.

\subsection{Gender differentiated vulnerability and labor force participation}

Initially the gendered vulnerability to climate change indicates the gendered division of labor. In developing countries, women have lower participation in labor force and mostly they hold lower paid and insecure job than man (Chant, 2013; Scott, 2014).Women are mainly employed in informal sector that is worst victim by climate change related disasters (WEDO, 2008). This is accelerated by women's unequal access to economic resources including income and property rights. ILO data in 2007 indicate that $59 \%$ of women in the total labor force in South Asia work as contributing family workers, compared to only $18 \%$ of men (ILO, 2008). Corresponding figures are $35 \%$ of women compared to $18 \%$ of men for Sub-Saharan Africa and $7 \%$ of women compared to $4 \%$ men in Latin America (ILO, 2008; FAO, 2010). Moreover, gender gaps in earnings persist across almost all employment categories, including informal wage employment and self-employment. Women receive less pay than men counterparts, ranging from $20-50 \%$ of men's salary in countries such as Afghanistan, to $57-79 \%$ in India, Pakistan and Bangladesh, putting them again at a disadvantage when it comes to financial resources to cope with climate change and disasters (FAO, 2010). Women in Bangladesh are engaged in various formal and informal sectors for the survival of their livelihoods. The table 1 shows a percentage feature of employment between men and women in formal and informal sectors in Bangladesh. 
Table 1. Employed persons by sector of employment, sex and residence, 2005-06 and 2010

(In percentage)

\begin{tabular}{lcccccc}
\hline \multirow{2}{*}{ Sector } & \multicolumn{2}{c}{ Bangladesh } & \multicolumn{2}{c}{ Urban } & \multicolumn{2}{c}{ Rural } \\
\cline { 2 - 7 } & Women & Men & Women & Men & Women & Men \\
\hline Total & 100.00 & 100.00 & 100.00 & 100.00 & 100.00 & 100.00 \\
Formal sector & 14.31 & 23.82 & 31.08 & 33.64 & 9.15 & 20.76 \\
Informal sector & 85.69 & 76.18 & 68.92 & 66.35 & 90.85 & 79.24 \\
\hline & \multicolumn{7}{c}{$\mathbf{2 0 0 5 - 0 6}$} \\
\hline Total & 100.0 & 100.0 & 100.0 & 100.0 & 100.0 & 100.0 \\
Formal sector & 7.7 & 14.5 & 19.0 & 27.8 & 4.4 & 10.7 \\
Informal sector & 92.3 & 85.5 & 81.0 & 72.2 & 95.6 & 89.3 \\
\hline
\end{tabular}

Source: Labor Force Survey, 2010, BBS

Table 2. Distribution of employed women by major occupation 1991- 2010

\begin{tabular}{lcccccc}
\hline Major occupation & $1990-91$ & $1995-96$ & $1999-00$ & $2002-03$ & $2005-06$ & 2010 \\
\hline Total & 100.0 & 100.0 & 100.0 & 100.0 & 100.00 & 100.0 \\
Professional technical & 7.5 & 7.2 & 4.4 & 4.1 & 4.38 & 3.2 \\
Administrative, Managerial & 0.4 & 0.1 & 0.2 & 0.0 & 0.19 & 0.6 \\
Clerical workers & 1.5 & 1.7 & 1.4 & 1.9 & 1.27 & 0.6 \\
Sales workers & 2.8 & 5.9 & 5.5 & 2.9 & 2.08 & 8.1 \\
Service workers & 17.5 & 15.6 & 17.5 & 9.7 & 7.67 & 8.0 \\
Agriculture, Forestry \& Fisheries & 47.6 & 41.7 & 46.3 & 58.6 & 68.33 & 64.8 \\
Production, Transport Labors & 21.8 & 27.8 & 24.2 & 22.8 & 16.06 & 14.0 \\
Not Adequately defined/Others & 0.9 & - & - & - & 0.01 & 0.7 \\
\hline
\end{tabular}

Source: Labor Force Survey (2002-03, 2005-06, 2010), BBS

The table 1 shows that in the years 2005-06, on average $(14.31 \%)$ women are employed in formal sector where $(85.69 \%)$ women are employed in informal sector. In case of men on average, $(23.82 \%)$ are employed in formal sector where $(76.18 \%)$ are employed in informal sector. In rural areas $(90.85 \%)$ of women and $(79.24 \%)$ of men are engaged in informal sector. In the year $2010,(7.7 \%)$ of women and $(14.5 \%)$ of men is seemed to engage in formal sector. This figure is the clear indication of women's less participation or engagement in formal sector in Bangladesh.
On the other hand, countries such as Nepal, India and Bangladesh have particularly high proportions of women in the agricultural sector, with approximately $(60 \%)$ of the women work force engaged in agriculture, to produce mainly rice and poultry (FAO, 2010). Information presented in table 2 shows the distribution of employed women (15 years and over) by major occupation in Bangladesh.

The share of the female labor force in agriculture, forestry and fisheries went through a sharp increase during last 10 year period (2000- 
2010). The share was 46.3 per cent in 2000 that increased to 58.6 per cent in 2003 and further increased at 64.8 per cent in 2010. This share indicates higher involvement of women in agriculture sector that is the most climate sensitive sector. Above statistics justified that "women are the main producers of the world's staple crops, providing up to $(90 \%)$ of the rural poor's food intake and producing $60-80 \%$ of the food in most developing countries"- (Aguilar et al., 2007). Again the agriculture sector is one of the sectors mostly affected by climate change. So, the vulnerability of women increases thereby.

In areas where unequal gender division of labor exists, climate change also increases the work burden of women. Such as after natural disaster, women's workload increases ranging from clean-up work to nursing the sick (Rodenberg, 2009). These are the traditional gender roles of women that ultimately push them to act as being overloaded with works other than incomegenerating activities (Solar, 2010; BRIDGE, 2008). They also have to play a crucial role in managing natural resource based livelihood activities such as collection of fuel wood and water. These activities consequently limit their involvement in personal income generation. The ultimate result is that women are affected most due to the impact of climate change.

\section{Gender-Specific Adaptation}

Women in developing countries experience particular constraints in their capacity to adapt to existing and predicted impacts of climate change. There are several studies highlighting the adaptive capacities of women across a range of regions, countries and agricultural practices (Ahmed and Fajber, 2009; Alston, 2013; Glazebrook, 2011; Segnestam, 2009). The literature indicates that adaptation strategies also vary across gender (Codjoe et al., 2012). Women are being forced to practice both traditional and non-traditional roles within and outside their family (Babugura, 2009). The fact is culturally and financially restricted poor women will be affected by the climate risk unevenly and will be even more restricted in response to the risk (Terry, 2009). Studies also note there may be factors limiting the strategies women are able to adapt (Djoudi and Brockhaus, 2011). Such as women usually have fewer resources - including assets, education and income - to respond to changes in weather patterns which alter familiar patterns of wind, rain, and temperature (Bradshaw and Linneker, 2014). At the household level, the ability to adapt to changes in the climate depends on control over economic resources such as land, money, credit as well as social safety for example freedom from violence (Lambrou and Piana, 2006).Women are often less able to adapt to climate change than men as they represent the majority of low-income earners in middle and low income countries (BRIDGE, 2008). Mitchell et al. (2007) gave a brief overview of climate change, women, and gender, noting that women will suffer the most, simply because they are women, and women are poorer. This finding indicates that rural poor women have started to adapt to a changing climate and can clearly articulate their needs such as better access to development services including training and information about adaptation strategies, and access to resources to implement effective strategies (Peralta, 2008; Mitchell et al., 2007). Women already have started raising their voice and secure their due rights and opportunities. To ensure equality in opportunities a consensus on gender equality is must.

\section{Future Policy Options for Gender Inclusion} Women experience differential impacts in climate change situation. These impacts also accelerate existing inequities in socially constructed gender roles, responsibilities and skewed power relations that tend to disadvantage women. Women will need to be at the centre of research, policy and action on climate change adaptation if these inequalities are to be avoided. However, women also provide important role in successful adaptation through their critical knowledge, experience and unique role in agriculture, food security, livelihoods, income generation, management of households and 
natural resources in diverse socio-cultural, political-economic and environmental institutions. At the same time, women are essential for developing sustainable adaptation options due to their knowledge, multiple responsibilities and as well as roles in productive areas. Study shows that women lack land rights, ownership rights for the means of production, technology, finances, information and training, related to climate adaptation (Rodenberg, 2009). To strengthen women's adaptation, it is necessary to enhance women's access, control and ownership of resources (such as land, livestock, property and income opportunities), and access to development of resources such as credit, information, and training. These are expected to be ensured through education, awareness raising and information programs addressing the gender based vulnerabilities. In many areas women are already adapting to the impacts of climate change and are fully aware of where their own and family needs (BRIDGE, 2008). Greater decision-making powers for women at the family and community level with regard to agricultural cultivation and the farming of new and more resistant crops can increase agricultural production, ensuring food security, and ultimately to a source of income.

\section{Conclusions}

From the literatures review, it is evident that climate change has emerged as a global crisis, but responses to it have so far been overly focused on scientific and economic solutions, rather than on the significant human and gender dimensions. So, it is important to put people at the centre of climate change responses, paying particular attention to the challenges and opportunities that climate change presents in the struggle for gender equality. There is a gap in evaluating the reasons behind the gender specific vulnerabilities in areas and context specific. Also the different coping mechanisms adopted by men and women in response to climate change have rarely been explored. Future research can emphasize on determining the appropriate coping strategies and adaptation priorities for men and women. More clarity is needed on the different vulnerability factors between men and women.

\section{References}

Aguilar, L., Araujo, A. and Quesada-Aquilar, A. 2007. Gender and climate change. The Global Gender and Climate Alliance.

Ahmad, N. 2012. Gender and climate change in Bangladesh: The role of institutions in reducing gender gaps in adaptation program. Social Development Working Papers. Paper No. 126. Washington, DC: The World Bank.

Ahmed, S. and Fajber, E. 2009. Engendering adaptation to climate variability in Gujarat, India. Gender and Development, 17(1):33-50.

Alam, K., Fatema, N. and Ahmed, W. B. 2008. Gender, Climate Change and Human Security in Bangladesh, Action Aid, Dhaka.

Alston, M. 2013. Women and Adaptation, Wiley Interdisciplinary Reviews: Climate Change. Available at: http://dx.doi.org/10.1002/wcc.232

(Accessed 15 March 2015).

Annecke, W. 2005. Climate Change, Energy Related Activities and the Likely Social Impacts on Women in Africa, in, Khamarunga, B. and Mongameli, M., (Eds), Capacity Building and Leadership Program: Equity and Gender in Climate Change.

Aoyagi, M., Suda, E. and Shinada,T. 2011.Gender Inclusion in Climate Change Adaptation. ADBI Working Paper 309. Tokyo: Asian Development Bank Institute.

Babugura, A. 2010. Gender and climate change: South Africa case study. Heinrich Böll Foundation Southern Africa. Cape Town, South Africa. 
Bangladesh Bureau of Statistics (BBS). (various years) Labor Force Survey Report, Bangladesh Bureau of Statistics (Dhaka, Government of Bangladesh).

Bartlett, S. 2008. Climate Change and Urban Children: Impacts and Implications for Adaptation in Low and Middle Income Countries, IIED Human Settlements Discussion Paper - Climate Change 2.

Bradshaw, S. and Linneker, B. 2014. Gender and Environmental Change in the Developing World. IIED Working Paper. IIED, London.

BRIDGE. 2008. Gender and Climate Change: mapping the linkages, a scoping study on knowledge and gaps, Institute of Development Studies, Sussex.

Chant, S. 2013. Cities through a "Gender Lens": a Golden "Urban Age" for women in the global South? Environment \& Urbanization, 25(1):9-29.

Climate Change Cell (CCC). 2009. Climate Change, Gender and Vulnerable Groups in Bangladesh, Dhaka: Climate Change Cell, DOE, MOEF; Component 4b, CDMP, MOFDM.

Codjoe, S.N., Atidoh, A., kafui, L. and Burkett, V. 2012. Gender and occupational perspectives on adaptation to climate extremes in the A farm Plains of Ghana. Climatic Change, 110(1-2): 431-454.

Devendra, C. and Chantalakhana, C. 2002. Animals, poor people and food insecurity: opportunities for improved livelihoods through efficient natural resource management. Outlook in Agriculture, 31 (3):161-175.

Djoudi, H. and Brockhaus, M. 2011. Is adaptation to climate change gender neutral? Lessons from communities dependent on livestock and forests in northern Mali. International Forestry Review, 13(2):123-135.
Engle, N.L. 2011. Adaptive capacity and its assessment. Global Environmental Change, 21 (2):647-656.

Eriksen, S.H. and Kelly, P.M. 2007. Developing credible vulnerability indicators for climate adaptation policy assessment. Mitigation and Adaptation Strategies for Global Change, 12 (4):495-524.

Farnworth, C. and Hutchings, J. 2009. "Organic Agriculture and Women's Empowerment". IFOAM. Germany.

Fisher, J. 2006. For Her It's the Big Issue: Putting Women at the Centre of Water Supply, Sanitation and Hygiene. Evidence Report. Water Supply and Sanitation Collaborative Council, Geneva, Switzerland.

Food and Agricultural Organization (FAO). 2010. Why Gender. Available at: http://www.fao.org/gender/genderhome/gender-why/why-gender/en/ (Accessed12 March 2015).

Food and Agriculture Organization (FAO). 2011. The State of Food and Agriculture 2010 2011: Women in Agriculture, Closing the Gender Gap for Development. Rome: Food and Agriculture Organization.

Glazebrook, T. 2011. Women and Climate Change: A Case Study from northeast Ghana, Hypatia, 26(4):762-782.

Hertel, T. W., Burke, M. B., and Lobell, D. B. 2010. The poverty implications of climate-induced crop yield changes by 2030. Global Environmental Change doi:10.1016/ j.gloenvcha.2010.07.001.

Hines, R. 2007. Natural Disasters and gender Inequalities: The 2004 Tsunami and the case of India, Race, Gender and Class, 14 (1-2):60.

Intergovernmental Panel on Climate Change (IPCC). 2007. Climate Change 2007: Synthesis report. Contribution of working groups I, II and III to the fourth 
assessment report of the Intergovernmental Panel on Climate Change.

International Labor Organization (ILO). 2008. Report of the Committee on Employment and Social Policy, Employment and labor market implications of climate change. Fourth Item on the Agenda, Governing Body, 303rd Session (Geneva), 2 p.

Kristjanson, P., Waters-Bayer, A., Johnson, N., Tipilda, A., Jemimah, N., Baltenweck, I., Grace, D. and MacMillan, S. 2010. Livestock and women's livelihoods: A review of the recent evidence. Nairobi, Kenya: International Livestock Research Institute.

Lambrou, Y. and Nelson, S. 2010. Farmers in a Changing Climate: Does Gender Matter? - Food Security in Andhra Pradesh, India, Food and Agricultural Organization (FAO), Rome.

Lambrou, Y. and Piana, G. 2006. 'Gender: the Missing Component of the Response to Climate Change'. Food and Agriculture Organization of the United Nations. Rome.

Mitchell, T., Tanner, T. and Lussier, K. 2007. We know what we need: South Asian women speak out on climate change adaptation. Institute of Development Studies, University of Sussex, UK.

Mondal, S. H. 2014. Women's Vulnerabilities due to the Impact of Climate Change: Case from Satkhira Region of Bangladesh, Global Journal of Human Social Science, 14 (5):46-52.

Money, J. 1986. Lovemaps: Clinical Concepts of Sexual/Erotic Health and Pathology, Paraphilia, and Gender Transposition in Childhood, Adolescence, and Maturity. New York: Irvington.

Nellemann, C., Verma, R., and Hislop, L. 2011. Women at the frontline of climate change: Gender risks and hopes. A Rapid
Response Assessment. United Nations Environment Programme, GRID-Arendal.

Neumayer, E. and Plumper, T. 2007. The Gendered Nature of Natural Disasters: The Impact of Catastrophic Events on the Gender Gap in Life Expectancy, 19812002, Association of American Geographers, 97 (3):551-566.

Nielsen J. and Reenberg A. 2010. Temporality and the Problem with Singling out Climate as a Current Driver of Change in a Small West African Village. Journal of Arid Environments, 74 (4):464-474.

O'Brien, K., Eriksen, S., Nygaard, L.P. and Schjolden, A. 2007. Why Different Interpretations of Vulnerability Matter in Climate Change Discourses, Climate Policy, 7 (1):73-88.

Peralta, A. 2008. Gender and Climate Change Finance: A case study from the Philippines. Women's Environment and Development Organization, New York, USA.

Ribeiro, N. and Chaúque, A. 2010. Gender and Climate change: Mozambique Case Study. Heinrich Böll Foundation Southern Africa, $42 \mathrm{p}$.

Rodenberg, B. 2009. Climate change adaptation from a gender perspective, Discussion Paper / Deutsches Institutfür Entwicklungspolitik - DIE, Bonn.

Scott, C. 2014. OPINION: Gender Inequality and Urban Informality. Climate Development Knowledge Network. Available http://cdkn.org/2014/06/opinion-genderinequality-andurban-informality-what-itmeans-for-climate-compatibledevelopment/ (Accessed 12 November 2014).

Segnestam, L. 2009. Division of Capitals-What role Does It Play for gender-Differentiated Vulnerability to Drought in Nicaragua? Community Development, 40(2):154-176. 
Solar, W. R. 2010. Rural Women, Gender, and Climate Change: Rural Women, Gender, and Climate Change: A Literature review invited perspectives on climate change impacts and processes of adaptation in Copyright@ Oxfam America, Cambodia.

Terry, G. 2009. No climate justice without gender justice: an overview of the issues. Gender and Development, 17(1):5-18.

United Nations (UN). 2014. General Assembly, Report of the Open Working Group of the General Assembly on Sustainable Development Goals, A/68/970, August.

Verma, R. 2007. "We Are the Land and the Land Is Us": The Complexities of Land Tenure for Pastoralists in Kenya, SARD
Initiative Study on Tenure Security for Pastoralists in Kenya. Food and Agricultural Organization (FAO), Rome.

Williamson, T., Hesseln, H. and Johnston, M. 2012. Adaptive Capacity Deficits and Adaptive Capacity of Economic Systems in Climate Change Vulnerability Assessment, Forest Policy and Economics, 15 (1):160-166.

Women's Environment and Development Organization (WEDO). 2008. Gender, climate change, and human security: Lessons from Bangladesh, Ghana, and Senegal. Available at: http://www.wedo.org/wpcontent/uploads/hsn-studyfinal-may-202008.pdf (Accessed 12 March 2015). 